\title{
Investigating Gut Permeability in Animal Models of Disease
}

\section{Marianela González-González, Camilo Díaz-Zepeda, Johana Eyzaguirre-Velásquez, Camila González-Arancibia, Javier A. Bravo and Marcela Julio-Pieper*}

Grupo de NeuroGastroBioquímica, Instituto de Química, Facultad de Ciencias, Pontificia Universidad Católica de Valparaíso, Valparaíso, Chile

A growing number of investigations report the association between gut permeability and intestinal or extra-intestinal disorders under the basis that translocation of gut luminal contents could affect tissue function, either directly or indirectly. Still, in many cases it is unknown whether disruption of the gut barrier is a causative agent or a consequence of these conditions. Adequate experimental models are therefore required to further understand the pathophysiology of health disorders associated to gut barrier disruption and to develop and test pharmacological treatments. Here, we review the current animal models that display enhanced intestinal permeability, and discuss (1) their suitability to address mechanistic questions, such as the association between gut barrier alterations and disease and (2) their validity to test potential treatments for pathologies that are characterized by enhanced intestinal permeability.

Keywords: gut, permeability, barrier, epithelium, gastrointestinal disorders

\section{INTRODUCTION}

Many clinical disorders are characterized or accompanied by GI alterations, including symptoms such as discomfort or pain, bloating and altered motility which can negatively impact a patient's quality of life. For example, irritable bowel syndrome, a chronic, relapsing GI problem (Spiller et al., 2007) with a high overall prevalence ranging from 10 to $20 \%$ of the population (Guarner et al., 2008), is also highly comorbid with other pathologies including depression and anxiety, cardiovascular disease and fibromyalgia (Cole et al., 2006; Mussell et al., 2008; Gros et al., 2009; Faresjo et al., 2013). In the past decade, this intricate connection between the GI and other systems has received deep attention allowing for the coining of terms such as gut-brain axis (GonzalezArancibia et al., 2016), gut-liver axis (Federico et al., 2016), or gut-kidney axis (Khoury et al., 2016). Likewise, the number of papers addressing the contribution of intestinal microbiota (which may be considered "an organ within an organ") aspects to the above axes has increased exponentially in the last few years.

The adequate relationship between GI physiology and overall homeostasis involves a variety of delicate functions; among these, the participation of gut motility, intestinal epithelial secretion and visceral perception mechanisms in association to systemic alterations have been somewhat explored (Duclos et al., 1991; Lackner et al., 2004; Zheyu et al., 2007; Yamamoto et al., 2008;

Abbreviations: CLP, cecal ligation and puncture; DSS, dextran sulfate sodium; ENS, enteric nervous system; FD4, fluorescein isothiocyanate-dextran 4,000 Da; FITC, fluorescein isothiocyanate; GI, gastrointestinal; HRP, horseradish peroxidase; IBD, inflammatory bowel disease; IL, interleukin; JAM, junctional adhesion molecule; PEG, polyethylene glycol; TEER, transepithelial electrical resistance; TNBS, trinitrobenzene sulfonic acid; ZO, zonula occludens. 
Diebel et al., 2015; Yamamoto-Furusho et al., 2015). However, the contribution of other complex responses such as those regulated by the ENS or the intestinal epithelial barrier to the development of GI and extraintestinal disorders are still largely unknown. Regarding the association between gut barrier modifications and disease, abundant but mostly observational data is available (see Table 1). These evidences strongly suggest the involvement of an altered barrier in either the origin or the manifestations of these diseases, although the exact mechanisms are yet to be investigated. A few recent temporal, genetic and twin studies have looked into the potential role of a dysfunctional gut barrier in the onset of disease (Uhlig et al., 2014; Tornai et al., 2017; Keita et al., 2018). Still, the pathogenesis of inflammatory gut diseases is unclear, and although the previous reports somewhat point to barrier-associated factors (including genetic predisposition and unfavorable luminal environment conditions) further exploration of this hypothesis is still needed. Appropriate animal models may allow addressing such mechanistic questions, while also allowing to test potential treatments for pathologies that are characterized by enhanced intestinal permeability.

\section{FACTORS INFLUENCING THE GUT BARRIER FUNCTION}

The GI tract has an estimated surface area of $32 \mathrm{~m}^{2}$ (Helander and Fandriks, 2014). Being constantly exposed to microbes and potentially damaging or immunogenic substances (i.e., bacterial, dietary and xenobiotic components and their metabolites) it requires a selective and efficient barrier function. This is

TABLE 1 | Disorders associated with increased gut permeability.

$\begin{array}{ll}\begin{array}{ll}\text { Gastrointestinal disorders associated } \\ \text { Inflammatory bowel disorders }\end{array} & \begin{array}{l}\text { Soderholm et al., 1999; } \\ \text { Vivinus-Nebot et al., 2014 }\end{array} \\ \begin{array}{ll}\text { Celiac disease } & \text { Heyman et al., 2012 } \\ \text { Food allergies } & \text { Perrier and Corthesy, 2011 } \\ \text { Infectious diarrhea } & \text { Sharpstone et al., 1999; Hoque } \\ \text { et al., 2012 }\end{array} \\ \begin{array}{ll}\text { Irritable bowel syndrome } & \text { Camilleri et al., 2012 } \\ \text { Extraintestinal disorders and conditions associated with gut } \\ \text { barrier alterations }\end{array} \\ \begin{array}{ll}\text { Critical illness and multiple } \\ \text { organ dysfunction syndrome }\end{array} \\ \text { Burn injury } & \text { Ziegler et al., 1988; Earley et al., 2010 } \\ \text { Heart failure } & \text { et al., 2015 } \\ \text { Renal failure } & \text { Sandek et al., 2007 } \\ & \text { Magnusson et al., 1991; Vaziri } \\ \text { Liver disease } & \text { et al., 2013 } \\ \text { Rheumatologic disorders } & \text { Schnabl, 2013 } \\ \text { Dermatologic disorders } & \text { Ciccia et al., 2010 } \\ \text { Humbert et al., 1991; Majamaa } & \text { and Isolauri, 1996 } \\ \text { Diabetes } & \text { Bosi et al., 2006; Sapone et al., } \\ & \text { 2006 } \\ \text { Depression } & \text { Maes et al., 2008 } \\ \text { Schizophrenia } & \text { Severance et al., 2013 } \\ & \\ & \end{array}$

composed of several main layers: more externally, the gut microbiota; a mucus gel coat acting as a physical diffusion layer; and the epithelium, responsible for secretion, absorption, endocrine and immune functions, to name a few.

Regarding the gut microbiota, it has been well shown that the absence of luminal bacteria at key developmental stages drastically affects the maturation of the gut barrier (Wagner et al., 2008; Sommer and Backhed, 2013). Animals reared in germfree conditions display striking alterations in the morphology as well as in several immune, biochemical and biophysical parameters of the intestinal barrier. Also these germ free animals have alterations in the ENS, such as reduced neuron excitability (McVey Neufeld et al., 2013). Likewise, reduced intestinal virome diversity and altered intestinal barrier function are associated not only with infectious and autoimmune diseases but also metabolic disorders and cardiovascular disease (Carding et al., 2017).

Most bacteria and viruses do not contact the gut epithelium directly due to the presence of mucus. The intestinal mucus gel coat is produced by a subset of epithelial cells known as goblet cells and contains mucins, highly glycosylated proteins that form a viscoelastic network. Important defense functions are exerted by the intestinal mucus: it acts as a physical diffusion barrier to pathogens and contains antimicrobial peptides and immunoglobulins, produced by mucosal Paneth cells and plasma B cells, respectively (Johansson et al., 2013).

The intestinal epithelium also restricts the passage of microbes and substances from the luminal space to the systemic compartment. Its main cell type are enterocytes which absorb nutrients, water and electrolytes and can also secrete water and electrolytes. Enterocytes connect to each other through protein structures, namely desmosomes and adherens junctions, integrins and tight junctions (Daneman and Rescigno, 2009). These protein complexes are key to modulate the paracellular transport of substances across the epithelium, which represents the predominant means of gut epithelial permeability (Suzuki, 2013). Tight junctions (TJ) allow the movement of water, small solutes and electrolytes between epithelial cells, but restrict the translocation of larger molecules. TJ function is dynamic and can be regulated by factors associated to cellular stress, gut microbes and dietary compounds (Galipeau and Verdu, 2016). The transepithelial transport of compounds with high molecular weight is achieved via the transcellular pathway, which includes the processes of carrier-dependent transport and endocytosis, important for nutrient absorption. Increased permeability via the transcellular but especially the paracellular pathway can allow for excessive translocation of microbial and diet-derived molecules, potentially contributing to inflammatory conditions (Galipeau and Verdu, 2016).

Another gut epithelial cell type are enteroendocrine cells, capable of releasing endocrine mediators. They have been called "sentinels of the intestinal environment" (Worthington et al., 2018) and are able to regulate intestinal inflammation by enhancing secretion of the anti-inflammatory mediator GLP-1 (Lebrun et al., 2017). According to the authors, gut injury-associated increase in permeability is believed to allow LPS access to stimulate a subtype of enteroendocrine cells, resulting in GLP-1 secretion. This peptide would 
favor mucosal integrity by attenuating local and systemic inflammation.

The gut mucosa is not only composed of epithelial cells. Immersed in the intestinal epithelium are immune cells which upon contact with luminal material are able to coordinate adequate responses either to prevent microbial invasion ( $\mathrm{Li}$ et al., 2012) or to dampen down exaggerated immune reactions (Turner, 2009). Additionally, these mucosal immune cells exert modulatory functions over the intestinal barrier; for example, $\mathrm{T}$ helper cell-derived cytokines can help modify the flux of molecules across tight junctions or cation pores (Turner, 2009). If microbes surpass the intestinal epithelium, they are eliminated by macrophages from the lamina propria (Kelsall, 2008) in a process characterized by the lack of a strong proinflammatory tone (Smythies et al., 2005). In addition, upon damage macrophages migrate to the injured area and promote epithelial tissue repair (Pull et al., 2005).

In addition to immune cells, the gut wall contains neurons which are another important aspect in the modulation of intestinal barrier permeability. Mediators released by the ENS, which is organized in submucosal and myenteric plexi, can modulate not only paracellular permeability, water/electrolyte transport and nutrient absorption but also wound healing, in particular the process of epithelial proliferation/differentiation (Neunlist et al., 2013).

Intestinal barrier function is critical for gut homeostasis. A breach in this barrier can be originated by improper function of one or more of its cell types, including inadequate interaction between epithelial cells associated not only to alterations of the tight junctions but also weakened intercellular adherent connections (Viggiano et al., 2015). As such, abnormal intestinal permeability is an important component in dysfunctional gut barrier-associated disorders such as IBD and celiac disease (Groschwitz and Hogan, 2009). Altered permeability has been associated to several human diseases (see Table 1) in the GI and other systems. The traditional view that defines increased permeability as a mere consequence of disease processes is now outdated; alterations in the translocation of luminal substances are currently being considered as part of disease etiopathogenesis (Keita et al., 2018). Therefore, there is increasing need for animal models of gut permeability not only to test palliative therapies but to further investigate disease etiology and subsequently propose novel pharmacological targets. Fortunately, many functional, cellular and biochemical features of the intestinal barrier are conserved among species; for example, a high degree of similarity is observed between tight junction proteins across vertebrates (Robinson et al., 2015; Brugman, 2016).

\section{METHODS FOR TESTING GUT PERMEABILITY AND OTHER MARKERS OF BARRIER DISRUPTION}

When testing for intestinal permeability, a variety of parameters can be evaluated. Moreover, the fact that permeability varies along the GI tract must be taken into account, being the small intestine more permeable than the large intestine (Mateer et al.,
2016). Excellent reviews are available (Wang et al., 2015; Fukui, 2016; Galipeau and Verdu, 2016) which summarize the most commonly used permeability tests for both basic and clinical research, in order to evaluate the status of epithelial barrier integrity, the pathophysiology of leaky gut alterations or to prove the effectiveness of treatment.

Briefly, methods for testing gut permeability in vivo involve the administration of a tracer molecule by oral gavage or intestinal instillation. Tracers commonly used are non-digestible sugars such as lactulose or mannitol, PEG, fluorescently labeled dextrans and ${ }^{51} \mathrm{Cr}$-EDTA (see Galipeau and Verdu, 2016 for applications, advantages and limitations of these and other tracers), which can be later quantified in urine or blood. The size of a tracer can indicate the probable route of permeability: for example, $4 \mathrm{kDa}$ dextrans are able to pass through the paracellular route. This is also the case for mannitol and ${ }^{51} \mathrm{Cr}$-EDTA. On the other hand, larger molecules like $40 \mathrm{kDa} \mathrm{HRP}$ are commonly associated to the transcellular pathway (Galipeau and Verdu, 2016). The output in most of these techniques is a single value of permeability, which does not allow to discern which region of the GI is being affected, and therefore must be used in combination with other methods (Galipeau and Verdu, 2016). Also, factors affecting the distribution and excretion of orally administered probes, such as gastric emptying, intestinal transit, bacterial degradation, intestinal blood flow, as well as the timing of blood or urinary collection should be taken into consideration (Bjarnason et al., 1995).

Short term culture of tissue explants for ex vivo permeability tests has the advantage of allowing for the evaluation of very specific regions of the GI tract and also maximizes data output in expensive or lengthy treatments. However, tissue viability is a major concern and therefore incubation times no longer than $3 \mathrm{~h}$ are recommended (Clarke, 2009). The use of everted gut sacs to measure the transit of fluorescent probes has the advantage of not demanding specialized equipment, but larger amounts of tissue are required (3-4 $\mathrm{cm}^{2}$ ) (MoyanoPorcile et al., 2015; Eyzaguirre-Velasquez et al., 2017). In the Ussing chamber, ion transport across the intestinal wall can be measured in very small segments of tissue $\left(1 \mathrm{~cm}^{2}\right)$ but a more expensive setup is necessary. Here, the degree of TEER is considered an inverse correlate to the extent of paracellular permeability (Clarke, 2009). Although there has been some debate around whether TEER represents transor paracellular permeability, its close association to the tight junction protein dynamics (Srinivasan et al., 2015) makes us agree to the latter. Since the apical and basolateral sides are kept in isolated chambers, the passage of tracers can also be evaluated. FITC-dextrans, ${ }^{51}$ Cr-EDTA and HRP have been used to evaluate paracellular and transcellular permeability, respectively (Galipeau and Verdu, 2016). The Ussing chamber can also be used to evaluate permeability across monolayers of cultured epithelial cells (Brown and O'Grady, 2008), such as the Caco-2 cell line, which polarize under appropriate growth conditions. In cell monolayers, TEER measurements can also be performed in an ohm-volt meter (Zhao et al., 2016), a simpler device when compared to the Ussing chamber + voltage clamp apparatus. 
In order to obtain comprehensive information regarding epithelial leakiness it is recommended that in vivo and ex vivo/in vitro tests of permeability are used in combination with the detection of permeability-associated biomarkers (Galipeau and Verdu, 2016). For example, the presence of microbial products or the corresponding antibodies in the blood is an indirect evidence of barrier breach (Tian et al., 2009; Vancamelbeke and Vermeire, 2017). These strategies allow for testing in a less invasive, non-terminal fashion but again, do not allow discerning which region of the GI is being affected. On the other hand, evaluating (a) mucosal morphology (including villus and/or crypt length, inflammatory cell infiltration, etc.) (Li et al., 2015), (b) the presence of tracer particles in pinocytic vesicles within gut absorptive cells (Worthington and Syrotuck, 1976), together with (c) tight junction/inflammatory protein and/or mRNA expression are more invasive, usually terminal strategies that provide information regarding the site and potential mechanism of damage (Steegenga et al., 2012; Hwang et al., 2013).

\section{STUDYING GUT BARRIER ALTERATIONS IN ANIMAL MODELS}

The gut barrier is structurally and biochemically conserved across species, as mentioned before. Both in humans and rodents the intestinal barrier function is highly sensitive to stress, dietary and microbiota changes. Therefore, we must consider that most animal models involving a modification in the environment could display changes in gut permeability to some extent. However, to the purpose of investigating mechanisms of disease and suitable treatments, a model should follow at least some of the following criteria (Vervliet and Raes, 2013): (1) face validity, meaning that the modifications observed in animal biochemistry, physiology and/or behavior should resemble those observed in human patients; (2) construct validity, which implies that the etiology of human disease was considered when establishing the model (i.e., alcohol is given to rats to model alcoholic liver disease) and (3) predictive validity, which means that the animal model should respond to interventions (such as pharmacological treatments) in the same way a human patient would. Vervliet and Raes (2013) propose that the relevance of a model relies on its external validity, which according to the authors depends largely on using combined evaluations of predictive, diagnostic and construct validity. In our opinion, depending on the particular use of a model (mechanistic studies, screening of therapeutic compounds, etc.) we could choose two or even one criteria of validity; however reaching all three would provide a more robust model.

With regards to gut barrier alterations, most animal models share a common feature: they display enhanced epithelial permeability. Rodents are typically used, although other animals, such as porcine (Lalles et al., 2007), equine (Marshall and Blikslager, 2011) and avian models (Jeurissen et al., 2002; Baxter et al., 2017), have also been described, to name a few. The last three are particularly useful to investigate veterinary conditions including early weaning, anti-inflammatory drug, feed contamination or restriction, respectively. However there are also reports indicating the suitability of these species to model human diseases that are associated with disrupted gut permeability, as we will mention later.

Intestinal barrier disruption can be achieved by directly intervening on the intestinal environment, or indirectly by targeting another system that communicates to the gut. The latter is the basis for stress- or lesion-induced models that display altered gut permeability. In some cases, however, it is difficult to discern whether a combined effect has been achieved: for example, DSS (an agent that can be added to the animal's drinking water) is commonly used to chemically damage the mouse or rat intestinal epithelium inducing epithelial leakiness and an inflammatory colitis that resembles IBD in humans (Randhawa et al., 2014), however, it could also indirectly affect the brain-gut axis by causing discomfort and stress to the rodent (Jain et al., 2015), which are known to also enhance intestinal permeability (Meddings and Swain, 2000). Taking this in consideration, the following classification of models refers only to the initial stimuli or intervention applied to the experimental animal (see Table 2 for a further description).

\section{Models in Which Barrier Dysfunction Is Established on the Gut}

Here, the initial intervention is either applied or originated at the GI lumen. Dietary and microbiota changes can protect the intestinal barrier function, which is the case for glutamine (Li et al., 1994), bacteria-derived lactic acid (Ren et al., 2018) and butyrate (Kelly et al., 2015). Other interventions disrupt the gut barrier, as in the case of DSS (Poritz et al., 2007), TNBS (Bregeon et al., 2016; Xu et al., 2018) or heavy metal supplementation (Zhai et al., 2016), low protein (EyzaguirreVelasquez et al., 2017) or high fat diet (Hamilton et al., 2015), infection (Guttman et al., 2006; Goossens et al., 2018) or CLP (Parida et al., 2015). These models can be considered to have good construct validity for organic diseases (i.e., those where morphological and/or biochemical features are altered) where barrier function is compromised. For example, DSS or TNBS supplementation in rodents and IL-10 knockout mice are well known models of colitis (Shi et al., 2014; Li et al., 2018; Xu et al., 2018), which is achieved through different mechanisms: DSS induces epithelial injury with exposure of the lamina propria and submucosa to luminal antigens, resulting in inflammation which ultimately alters the gut barrier; TNBS acts as a hapten and also induces inflammation but through Th1-mediated immune responses, which has been shown both in murine (Low et al., 2013) and swine models (Bregeon et al., 2016). IL-10 knockout mice spontaneously develop bowel inflammation, which is associated to colon dysbiosis (Shi et al., 2014). On the other hand, CLP is used to simulate sepsis (Yoseph et al., 2016).

Human gut biochemical features that are commonly associated with perpetuation of intestinal barrier loss (i.e., local proinflammatory cytokines, proteases, neurotransmitters, pathogen-derived products) have been functionally evaluated by 
TABLE 2 | Examples of experimental approaches to model increased gut permeability.

\section{Species and type of model \\ Intestinal models \\ Mice, oral cadmium exposure (100 mg/ $\mathrm{CdCl}_{2}$ for 8 week) \\ Mice, sepsis induced by CLP \\ Rats, allergy induced by oral} administration of ovoalbumin

Mice, colitis induced by oral administration of DSS (3\% for up to 7 days)

Rats, colitis induced by anal infusion of TNBS (20 mg)

Swine, rectal mucosal lesions induced by TNBS enema (15 mg/ml, $15 \mathrm{~min}$ )

Mice, infection with Citrobacter rodentium

Chickens, infection with several Eimeria species

Mice, CLP

Chickens, $24 \mathrm{~h}$ feed restriction

Rats, low protein diet (4\% for 20 days)

Rats, high fat diet (45\% for up to 6 weeks)

\section{Extraintestinal models}

Mice, pneumonia induced by Pseudomonas aeruginosa.

Mice, low-dose ionizing radiation (4 Gy)

Mice, burn injury $\left(85^{\circ} \mathrm{C}, 20 \%\right.$ body area)

Rats, brain injury (20 g from a height of $30 \mathrm{~cm}$ )

\section{Observations}

Increased gut permeability and proinflammatory cytokine expression. Decreased tight junction protein expression. Reversed by oral probiotic administration

Enhanced permeability to FD4 and increased expression of Claudin 2 and JAM-A. Decreased expression of Claudin 5 and Occludin

Erosive damage in small intestine. Increased lactulose/mannitol ratio. Altered morphology of tight junctions and decreased expression of tight junction proteins

Loss of ZO-1 and increased permeability to Evan's Blue dye

Decreased expression of ZO-1 and Occludin in colon. Increased levels of endotoxin in serum and colon

Acute increase in paracellular and transcellular permeability. Disrupted localization of ZO-1 in rectal mucosa Tight junction disruption associated to attachment of the pathogenic bacteria to the cells

Increased expression of ovotransferrin in the colon. Increased fecal ovotransferrin levels

Increased plasma bacterial load and TNF expression

Increased permeability to FD4

Decreased mucosal tight junction protein expression and reduced TEER in the colon.

Increased flux of HRP flux in correlation with time on the diet

Enhanced permeability to FD4 and increased expression of Claudin 2 and JAM-A. Decreased expression of Claudin 5, ZO-1 and Occludin Redistribution of tight junctions, adherens junctions and actin cytoskeleton in colon mucosa. Increased permeability to FITC-inulin

Increased permeability to FD4. Reduced expression of Claudin 4 and 8

Increased lactulose/mannitol ratio. This is reversed by oral probiotic administration
Mechanism proposed by author

Genotoxicity, death of epithelial cells, damage to tight junctions, gut dysbiosis

NA

Yoseph et al., 2016

Inflammation in intestinal tract during allergy induction by OVA

Toxic effect on the colonic epithelial cells and crypts leading to changes in the TJ complex and in mucosal permeability prior to the inflammatory infiltrate

Hapten-induced chronic inflammation

Inflammation associated to overexpression of $\mathrm{IL}-1 \beta, \mathrm{IL}-4, \mathrm{IL}-10$, IFN $\alpha$ and IFN $\gamma$

Alteration of claudin-3 localization dependent on the intimate attachment of the pathogen to the colonic enterocytes, and independent on inflammation

Release of pro-inflammatory cytokines due to coccidial-induced inflammatory response in the gut

Excessive bacterial load leading to septic inflammatory response

Increased levels of plasma corticosterone leading to disruption of gut barrier integrity and local inflammation

Changes in epithelial cell differentiation

Early and region-specific changes in the gut microbiota which correlate with alterations in gut epithelial function

NA

Ablation of crypt cell proliferation, mitotic catastrophe, and apoptosis leading to gastrointestinal mucositis

Rapid and systemic inflammatory response, including mesenteric vasoconstriction leading to gut hypoxia and cell death

Intestinal ischemia and hypoxia. Enhanced cell catabolism resulting in depletion of intestinal mucosa main fuel.
Xu et al., 2018

Yoseph et al., 2016

Poritz et al., 2007

Bregeon et al., 2016

Guttman et al., 2006

Goossens et al., 2018

Parida et al., 2015

Baxter et al., 2017

Eyzaguirre-Velasquez et al., 2017

Hamilton et al., 2015

Shukla et al., 2016

Earley et al., 2015

Zhang and Jiang, 2015 
TABLE 2 | Continued

\begin{tabular}{|c|c|c|c|}
\hline Species and type of model & Observations & Mechanism proposed by author & Reference \\
\hline $\begin{array}{l}\text { Rats, hyperthermia (up to } \\
42.5^{\circ} \mathrm{C}, 90 \mathrm{~min} \text { ) }\end{array}$ & $\begin{array}{l}\text { Increased gut permeability to FD4 and } \\
\text { marked intestinal epithelial damage }\end{array}$ & $\begin{array}{l}\text { Reduced blood flow to the Gl tract resulting in } \\
\text { hypoxia, free radical production, ATP depletion, } \\
\text { acidosis, and disruption of intestinal epithelial } \\
\text { membranes that results in enterocyte necrosis }\end{array}$ & Lambert et al., 2002 \\
\hline $\begin{array}{l}\text { Mice, acute cold exposure } \\
\left(4^{\circ} \mathrm{C}, 30 \mathrm{~min}\right)\end{array}$ & $\begin{array}{l}\text { Increased permeability to L-arabinose. } \\
\text { Increased Claudin } 2 \text { mRNA expression }\end{array}$ & $\begin{array}{l}\text { Adjustments to the tight junction in order to } \\
\text { increase paracellular permeability to } \\
\text { nutrient-sized molecules, to meet enhanced } \\
\text { digestive/absorptive demand }\end{array}$ & Price et al., 2013 \\
\hline Rats, acute restraint stress (2 h) & $\begin{array}{l}\text { Transient increase in ileal epithelial } \\
\text { permeability to alanthanum tracer. } \\
\text { Irregular distribution of occludin and } \\
\text { ZO-1 }\end{array}$ & $\begin{array}{l}\text { Stress-induced contraction of the actin } \\
\text { cytoskeleton increasing the distance between } \\
\text { adjacent enterocytes }\end{array}$ & Mazzon et al., 2002 \\
\hline $\begin{array}{l}\text { Rats, water avoidance stress } \\
\text { ( } 1 \mathrm{~h} \text { daily for } 7 \text { days) }\end{array}$ & $\begin{array}{l}\text { Decreased TEER, increased flux of } \\
\text { HRP and altered expression of Claudin } \\
2, \text { JAM-A and ZO- } 1 \text { in colon }\end{array}$ & $\begin{array}{l}\text { Sub-inflammatory increase in proinflammatory } \\
\text { cytokines which mediates the alteration of TJ } \\
\text { protein expression }\end{array}$ & Hattay et al., 2017 \\
\hline $\begin{array}{l}\text { Mice, intensive treadmill } \\
\text { exercise ( } 80 \% \text { of their } \mathrm{VO}_{2} \max \\
\text { until exhaustion) }\end{array}$ & $\begin{array}{l}\text { Increased permeability to FD4, } \\
\text { electrogenic ion transport and tissue } \\
\text { conductance of the small intestine. Also } \\
\text { enhanced apoptosis of small intestinal } \\
\text { epithelial cells }\end{array}$ & $\begin{array}{l}\text { Gastrointestinal ischemia-associated alterations } \\
\text { in epithelial integrity followed by fast repair } \\
\text { processes in the duodenum }\end{array}$ & Gutekunst et al., 2014 \\
\hline
\end{tabular}

CLP: cecal ligation and puncture. DSS: dextran sulfate sodium. FD4: fluorescein isothiocyanate-dextran 4,000 Da. HRP: horseradish peroxidase. IFN: interferon. IL: interleukin. JAM: junctional adhesion molecule. MLCK: myosin light chain kinase. NA: not available. TEER: transepithelial electrical resistance. TNBS: trinitrobenzene sulfonic acid. ZO: zonula occludens.

using well described gut-derived cell lines such as Caco-2. Here, a cell monolayer is exposed to cleared supernatants obtained from intestinal biopsies, explants or feces. Later, intestinal barrier markers and permeability parameters can be assessed in the cells (Piche et al., 2009). We believe that similar experimental designs could be used to demonstrate that soluble mediators generated at the animal model gut, which are considered to be involved in epithelial barrier disease mechanism, are functionally relevant.

\section{Models in Which Gut Barrier Dysfunction Is Established Outside the Gut}

Lesion induction by skin burn, head trauma, radiation as well as shock induced by hyper- or hypothermia are all considered indirect interventions that increase intestinal permeability. Similar gut alterations are observed when acute or chronic stress is induced by brief water deprivation, motion restraint, overcrowding or forced swim, among others. In all the above cases, the initial disruption is believed to affect systems that are different from the GI, and therefore gut permeability is indirectly enhanced. From the construct validity point of view, these strategies may be more adequate to model barrier function alterations that are subsequent to previous stress or injury, or functional diseases where no morphological and/or biochemical markers are known yet.

Not every increase in gut permeability is associated to disease; for example, exhausting exercise in athletes is followed by marked increases in gut permeability (Lambert, 2009), without known pathological consequences that aren't attributable to dehydration or heat stress (de Oliveira et al., 2014). Therefore, an effort should be made to prove causality, especially when the injuring stimuli is not directly related to intestinal physiology in an animal model, but gut permeability is proposed as part of the disease mechanism.

\section{CONCLUDING REMARKS}

Empiric evidence obtained from animal models, including not only correlation studies but also mechanistic designs allow us to propose (or refuse) particular aspects of barrier function as potential pathways to disease. For example, altered intestinal permeability is described in many chronic diseases; whether it constitutes a risk factor or a target for developing therapies must be established by means of a proper experimental setup.

The complexity of gut barrier function has a lot to do with its connections to other systems. Most of these are not fully understood and therefore, this research is still at its early years. Concomitant alterations in the microbial community, ENS and local immune system should be taken into consideration when interpreting data from animal models, in order to propose significant mechanisms or effective therapeutic strategies for multifactorial diseases. Some future research aims include: 
- Implementing experimental approaches that allow for continuous monitoring of these events, taking into consideration that gut barrier function and especially epithelial permeability are dynamic phenomena.

- Investigating the variability of sign/symptom severity that arises from applying single or multiple stimuli, in order to better represent acute or chronic features of disease.

- Including more detailed characterization by reporting several outputs that reflect different elements and consequences of a gut barrier breach, i.e., permeability tests + intestinal epithelial changes + microbial products in the blood + inflammatory changes in the gut or other organs.

- Minimizing confounding factors such as inconsistencies at sampling timing, unwanted stress, and all environmental variables that can disturb barrier function.

\section{GLOSSARY}

\section{Dysbiosis}

Imbalance in the microbial communities that reside a living organism, either by changes in quantity or quality.

\section{ENS}

Intrinsic nervous system of the GI tract. It regulates vital GI functions, including motility, secretion, local immunity, and tissue repair.

\section{REFERENCES}

Baxter, M. F. A., Merino-Guzman, R., Latorre, J. D., Mahaffey, B. D., Yang, Y., Teague, K. D., et al. (2017). Optimizing fluorescein isothiocyanate dextran measurement as a biomarker in a 24 -h feed restriction model to induce gut permeability in broiler chickens. Front. Vet. Sci. 4:56. doi: 10.3389/fvets.2017. 00056

Bjarnason, I., MacPherson, A., and Hollander, D. (1995). Intestinal permeability: an overview. Gastroenterology 108, 1566-1581. doi: 10.1016/0016-5085(95)90708-4

Bosi, E., Molteni, L., Radaelli, M. G., Folini, L., Fermo, I., Bazzigaluppi, E., et al. (2006). Increased intestinal permeability precedes clinical onset of type 1 diabetes. Diabetologia 49, 2824-2827. doi: 10.1007/s00125-006-0465-3

Bregeon, J., Coron, E., Da Silva, A. C., Jaulin, J., Aubert, P., Chevalier, J., et al. (2016). Sacral nerve stimulation enhances early intestinal mucosal repair following mucosal injury in a pig model. J. Physiol. 594, 4309-4323. doi: 10. 1113/JP271783

Brown, D. R., and O'Grady, S. M. (2008). The Ussing chamber and measurement of drug actions on mucosal ion transport. Curr. Protoc. Pharmacol. 41, 7.12.17.12.17. doi: 10.1002/0471141755.ph0712s41

Brugman, S. (2016). The zebrafish as a model to study intestinal inflammation. Dev. Comp. Immunol. 64, 82-92. doi: 10.1016/j.dci.2016.02.020

Camilleri, M., Lasch, K., and Zhou, W. (2012). Irritable bowel syndrome: methods, mechanisms, and pathophysiology. The confluence of increased permeability, inflammation, and pain in irritable bowel syndrome. Am. J. Physiol. Gastrointest. Liver Physiol. 303, G775-G785. doi: 10.1152/ajpgi.00155. 2012

Carding, S. R., Davis, N., and Hoyles, L. (2017). Review article: the human intestinal virome in health and disease. Aliment. Pharmacol. Ther. 46, 800-815. doi: 10.1111/apt.14280

Chen, T., Liu, X., Ma, L., He, W., Li, W., Cao, Y., et al. (2014). Food allergens affect the intestinal tight junction permeability in inducing intestinal food allergy in

\section{Microbiota/Microbiome}

Microbiota is the collection of bacteria, viruses, fungi, and other microorganisms that reside a living organism. Microbiome is the name given to the genes contained in these microbes.

\section{Tight Junctions}

Multiprotein complexes that join two adjacent cells together to form a barrier. The connection involves transmembrane and scaffold proteins, as well as cytoskeleton components.

\section{Virome}

Collection of viruses and associated nucleic acids that reside a living organism.

\section{AUTHOR CONTRIBUTIONS}

MJ-P drafted the first version and made Table 1. MJ-P and JB supervised the manuscript. MG-G, CD-Z, JE-V, and CG-A made Table 2. All authors revised the manuscript, approved the final version of the manuscript, and evaluated retrieved papers and their reference lists to identify additional relevant articles.

\section{FUNDING}

The authors and their work were supported by grants from Fondecyt 1140776 and Fondecyt 1181019.

rats. Asian Pac. J. Allergy Immunol. 32, 345-353. doi: 10.12932/AP0443.32.4. 2014

Ciccia, F., Bombardieri, M., Rizzo, A., Principato, A., Giardina, A. R., Raiata, F., et al. (2010). Over-expression of paneth cell-derived anti-microbial peptides in the gut of patients with ankylosing spondylitis and subclinical intestinal inflammation. Rheumatology 49, 2076-2083. doi: 10.1093/rheumatology/ keq239

Clarke, L. L. (2009). A guide to Ussing chamber studies of mouse intestine. Am. J. Physiol. Gastrointest. Liver Physiol. 296, G1151-G1166. doi: 10.1152/ajpgi. 90649.2008

Cole, J. A., Rothman, K. J., Cabral, H. J., Zhang, Y., and Farraye, F. A. (2006). Migraine, fibromyalgia, and depression among people with IBS: a prevalence study. BMC Gastroenterol. 6:26. doi: 10.1186/1471-230X-6-26

Daneman, R., and Rescigno, M. (2009). The gut immune barrier and the bloodbrain barrier: are they so different? Immunity 31, 722-735. doi: 10.1016/j. immuni.2009.09.012

de Oliveira, E. P., Burini, R. C., and Jeukendrup, A. (2014). Gastrointestinal complaints during exercise: prevalence, etiology, and nutritional recommendations. Sports Med. 44(Suppl. 1), S79-S85. doi: 10.1007/s40279014-0153-2

Diebel, M. E., Diebel, L. N., Manke, C. W., and Liberati, D. M. (2015). Estrogen modulates intestinal mucus physiochemical properties and protects against oxidant injury. J. Trauma. Acute Care Surg. 78, 94-99. doi: 10.1097/TA. 0000000000000499

Duclos, B., Bories, P., Mathieu-Daude, J. C., and Michel, H. (1991). Jejunal permeability to water and electrolytes in patients with chronic intrahepatic hypertension: evidence for a role of aldosterone. Gut 32, 640-644. doi: 10.1136/ gut.32.6.640

Earley, Z. M., Akhtar, S., Green, S. J., Naqib, A., Khan, O., Cannon, A. R., et al. (2015). Burn injury alters the intestinal microbiome and increases gut permeability and bacterial translocation. PLoS One 10:e0129996. doi: 10.1371/ journal.pone.0129996 
Eyzaguirre-Velasquez, J., Olavarria-Ramirez, L., Gonzalez-Arancibia, C., DiazMerino, C., Ariz, R., Lopez, S., et al. (2017). Protein malnutrition during juvenile age increases ileal and colonic permeability in the rat. J. Pediatr. Gastroenterol. Nutr. 64, 707-712. doi: 10.1097/MPG.0000000000001324

Faresjo, A., Grodzinsky, E., Hallert, C., and Timpka, T. (2013). Patients with irritable bowel syndrome are more burdened by co-morbidity and worry about serious diseases than healthy controls-eight years follow-up of IBS patients in primary care. BMC Public Health 13:832. doi: 10.1186/1471-2458-13-832

Federico, A., Dallio, M., Godos, J., Loguercio, C., and Salomone, F. (2016). Targeting gut-liver axis for the treatment of nonalcoholic steatohepatitis: translational and clinical evidence. Transl. Res. 167, 116-124. doi: 10.1016/j.trsl. 2015.08 .002

Fukui, H. (2016). Increased intestinal permeability and decreased barrier function: does it really influence the risk of inflammation? Inflamm. Intest. Dis. 1, 135-145. doi: 10.1159/000447252

Galipeau, H. J., and Verdu, E. F. (2016). The complex task of measuring intestinal permeability in basic and clinical science. Neurogastroenterol. Motil. 28, 957965. doi: $10.1111 / \mathrm{nmo} .12871$

Gonzalez-Arancibia, C., Escobar-Luna, J., Barrera-Bugueno, C., Diaz-Zepeda, C., Gonzalez-Toro, M. P., Olavarria-Ramirez, L., et al. (2016). What goes around comes around: novel pharmacological targets in the gut-brain axis. Therap. Adv. Gastroenterol. 9, 339-353. doi: 10.1177/1756283X16630718

Goossens, E., Debyser, G., Callens, C., De Gussem, M., Dedeurwaerder, A., Devreese, B., et al. (2018). Elevated faecal ovotransferrin concentrations are indicative for intestinal barrier failure in broiler chickens. Vet. Res. 49, 51. doi: 10.1186/s13567-018-0548-4

Gros, D. F., Antony, M. M., McCabe, R. E., and Swinson, R. P. (2009). Frequency and severity of the symptoms of irritable bowel syndrome across the anxiety disorders and depression. J. Anxiety Disord. 23, 290-296. doi: 10.1016/j.janxdis. 2008.08.004

Groschwitz, K. R., and Hogan, S. P. (2009). Intestinal barrier function: molecular regulation and disease pathogenesis. J. Allergy Clin. Immunol. 124, 3-20; quiz 21-22. doi: 10.1016/j.jaci.2009.05.038

Guarner, F., Lazaro, S., Gascon, E., Royo, M., Eximan, and Herrero, E. (2008). Map of Digestive Disorders \& Diseases, World Gastroenterology Organization. Milwaukee, WI: World Gastroenterology Organization.

Gutekunst, K., Kruger, K., August, C., Diener, M., and Mooren, F. C. (2014). Acute exercises induce disorders of the gastrointestinal integrity in a murine model. Eur. J. Appl. Physiol. 114, 609-617. doi: 10.1007/s00421-013-2791-8

Guttman, J. A., Samji, F. N., Li, Y., Vogl, A. W., and Finlay, B. B. (2006). Evidence that tight junctions are disrupted due to intimate bacterial contact and not inflammation during attaching and effacing pathogen infection in vivo. Infect. Immun. 74, 6075-6084. doi: 10.1128/IAI.00721-06

Hamilton, M. K., Boudry, G., Lemay, D. G., and Raybould, H. E. (2015). Changes in intestinal barrier function and gut microbiota in high-fat diet-fed rats are dynamic and region dependent. Am. J. Physiol. Gastrointest. Liver Physiol. 308, G840-G851. doi: 10.1152/ajpgi.00029.2015

Hattay, P., Prusator, D. K., Tran, L., and Greenwood-Van Meerveld, B. (2017). Psychological stress-induced colonic barrier dysfunction: role of immunemediated mechanisms. Neurogastroenterol. Motil. 29:e13043. doi: 10.1111/nmo. 13043

Helander, H. F., and Fandriks, L. (2014). Surface area of the digestive tract revisited. Scand. J. Gastroenterol. 49, 681-689. doi: 10.3109/00365521.2014. 898326

Heyman, M., Abed, J., Lebreton, C., and Cerf-Bensussan, N. (2012). Intestinal permeability in coeliac disease: insight into mechanisms and relevance to pathogenesis. Gut 61, 1355-1364. doi: 10.1136/gutjnl-2011-300327

Hoque, K. M., Chakraborty, S., Sheikh, I. A., and Woodward, O. M. (2012), New advances in the pathophysiology of intestinal ion transport and barrier function in diarrhea and the impact on therapy. Expert Rev. Anti Infect. Ther. 10, 687-699. doi: 10.1586/eri.12.47

Humbert, P., Bidet, A., Treffel, P., Drobacheff, C., and Agache, P. (1991). Intestinal permeability in patients with psoriasis. J. Dermatol. Sci. 2, 324-326. doi: 10. 1016/0923-1811(91)90057-5

Hwang, I., An, B. S., Yang, H., Kang, H. S., Jung, E. M., and Jeung, E. B. (2013). Tissue-specific expression of occludin, zona occludens-1, and junction adhesion molecule $\mathrm{A}$ in the duodenum, ileum, colon, kidney, liver, lung, brain, and skeletal muscle of C57BL mice. J. Physiol. Pharmacol. 64, 11-18.
Jain, P., Hassan, A. M., Koyani, C. N., Mayerhofer, R., Reichmann, F., Farzi, A., et al. (2015). Behavioral and molecular processing of visceral pain in the brain of mice: impact of colitis and psychological stress. Front. Behav. Neurosci. 9:177. doi: 10.3389/fnbeh.2015.00177

Jeurissen, S. H., Lewis, F., van der Klis, J. D., Mroz, Z., Rebel, J. M., and ter Huurne, A. A. (2002). Parameters and techniques to determine intestinal health of poultry as constituted by immunity, integrity, and functionality. Curr. Issues Intest. Microbiol. 3, 1-14.

Johansson, M. E., Sjovall, H., and Hansson, G. C. (2013). The gastrointestinal mucus system in health and disease. Nat. Rev. Gastroenterol. Hepatol. 10, 352-361. doi: 10.1038/nrgastro.2013.35

Keita, A. V., Lindqvist, C. M., Ost, A., Magana, C. D. L., Schoultz, I., and Halfvarson, J. (2018). Gut barrier dysfunction - a primary defect in twins with Crohn's disease predominantly caused by genetic predisposition. J. Crohns Colitis 12, 1200-1209. doi: 10.1093/ecco-jcc/jjy045

Kelly, C. J., Zheng, L., Campbell, E. L., Saeedi, B., Scholz, C. C., Bayless, A. J., et al. (2015). Crosstalk between microbiota-derived short-chain fatty acids and intestinal epithelial HIF augments tissue barrier function. Cell Host Microbe 17, 662-671. doi: 10.1016/j.chom.2015.03.005

Kelsall, B. (2008). Recent progress in understanding the phenotype and function of intestinal dendritic cells and macrophages. Mucosal Immunol. 1, 460-469. doi: $10.1038 / \mathrm{mi} .2008 .61$

Khoury, T., Tzukert, K., Abel, R., Abu Rmeileh, A., Levi, R., and Ilan, Y. (2016). The gut-kidney axis in chronic renal failure: a new potential target for therapy. Hemodial. Int. 21, 323-334. doi: 10.1111/hdi.12486

Lackner, J. M., Quigley, B. M., and Blanchard, E. B. (2004). Depression and abdominal pain in IBS patients: the mediating role of catastrophizing. Psychosom. Med. 66, 435-441.

Lalles, J. P., Bosi, P., Smidt, H., and Stokes, C. R. (2007). Nutritional management of gut health in pigs around weaning. Proc. Nutr. Soc. 66, 260-268. doi: 10.1017/ S0029665107005484

Lambert, G. P. (2009). Stress-induced gastrointestinal barrier dysfunction and its inflammatory effects. J Anim Sci 87(Suppl.), E101-E108. doi: 10.2527/jas.20081339

Lambert, G. P., Gisolfi, C. V., Berg, D. J., Moseley, P. L., Oberley, L. W., and Kregel, K. C. (2002). Selected contribution: hyperthermia-induced intestinal permeability and the role of oxidative and nitrosative stress. J. Appl. Physiol. 92, 1750-1761; discussion 1749. doi: 10.1152/japplphysiol.00787.2001

Lebrun, L. J., Lenaerts, K., Kiers, D., Pais de Barros, J. P., Le Guern, N., Plesnik, J., et al. (2017). Enteroendocrine L cells sense LPS after gut barrier injury to enhance GLP-1 secretion. Cell Rep. 21, 1160-1168. doi: 10.1016/j.celrep.2017. 10.008

Li, J., Langkamp-Henken, B., Suzuki, K., and Stahlgren, L. H. (1994). Glutamine prevents parenteral nutrition-induced increases in intestinal permeability. J. Parenter. Enteral. Nutr. 18, 303-307. doi: 10.1177/014860719401800404

Li, M., Liang, P., Li, Z., Wang, Y., Zhang, G., Gao, H., et al. (2015). Fecal microbiota transplantation and bacterial consortium transplantation have comparable effects on the re-establishment of mucosal barrier function in mice with intestinal dysbiosis. Front. Microbiol. 6:692. doi: 10.3389/fmicb.2015.00692

Li, Y. H., Adam, R., Colombel, J. F., and Bian, Z. X. (2018). A characterization of pro-inflammatory cytokines in dextran sulfate sodium-induced chronic relapsing colitis mice model. Int. Immunopharmacol. 60, 194-201. doi: 10.1016/ j.intimp.2018.05.001

Li, Z., Zhang, C., Zhou, Z., Zhang, J., Zhang, J., and Tian, Z. (2012). Small intestinal intraepithelial lymphocytes expressing CD8 and $\mathrm{T}$ cell receptor gammadelta are involved in bacterial clearance during Salmonella enterica serovar Typhimurium infection. Infect. Immun. 80, 565-574. doi: 10.1128/IAI. 05078-11

Low, D., Nguyen, D. D., and Mizoguchi, E. (2013). Animal models of ulcerative colitis and their application in drug research. Drug Des. Devel. Ther. 7, 13411357. doi: 10.2147/DDDT.S40107

Maes, M., Kubera, M., and Leunis, J. C. (2008). The gut-brain barrier in major depression: intestinal mucosal dysfunction with an increased translocation of LPS from gram negative enterobacteria (leaky gut) plays a role in the inflammatory pathophysiology of depression. Neuro Endocrinol. Lett. 29, $117-124$.

Magnusson, M., Magnusson, K. E., Sundqvist, T., and Denneberg, T. (1991). Impaired intestinal barrier function measured by differently sized polyethylene 
glycols in patients with chronic renal failure. Gut 32, 754-759. doi: 10.1136/gut. 32.7.754

Majamaa, H., and Isolauri, E. (1996). Evaluation of the gut mucosal barrier: evidence for increased antigen transfer in children with atopic eczema. J. Allergy Clin. Immunol. 97, 985-990. doi: 10.1016/S0091-6749(96)80074-1

Marshall, J. F., and Blikslager, A. T. (2011). The effect of nonsteroidal antiinflammatory drugs on the equine intestine. Equine Vet. J. Suppl. 43, 140-144. doi: 10.1111/j.2042-3306.2011.00398.x

Mateer, S. W., Cardona, J., Marks, E., Goggin, B. J., Hua, S., and Keely, S. (2016). Ex vivo intestinal sacs to assess mucosal permeability in models of gastrointestinal disease. J. Vis. Exp. 108:e53250. doi: 10.3791/53250

Mazzon, E., Sturniolo, G. C., Puzzolo, D., Frisina, N., and Fries, W. (2002). Effect of stress on the paracellular barrier in the rat ileum. Gut 51, 507-513. doi: 10.1136/gut.51.4.507

McVey Neufeld, K. A., Mao, Y. K., Bienenstock, J., Foster, J. A., and Kunze, W. A. (2013). The microbiome is essential for normal gut intrinsic primary afferent neuron excitability in the mouse. Neurogastroenterol. Motil. 25, 183-e188. doi: 10.1111/nmo. 12049

Meddings, J. B., and Swain, M. G. (2000). Environmental stress-induced gastrointestinal permeability is mediated by endogenous glucocorticoids in the rat. Gastroenterology 119, 1019-1028. doi: 10.1053/gast.2000.18152

Moussaoui, N., Braniste, V., Ait-Belgnaoui, A., Gabanou, M., Sekkal, S., Olier, M., et al. (2014). Changes in intestinal glucocorticoid sensitivity in early life shape the risk of epithelial barrier defect in maternal-deprived rats. PLoS One 9:e88382. doi: 10.1371/journal.pone.0088382

Moyano-Porcile, V., Olavarria-Ramirez, L., Gonzalez-Arancibia, C., Bravo, J. A., and Julio-Pieper, M. (2015). Short-term effects of Poly(I:C) on gut permeability. Pharmacol. Res. 101, 130-136. doi: 10.1016/j.phrs.2015.06.016

Mussell, M., Kroenke, K., Spitzer, R. L., Williams, J. B., Herzog, W., and Lowe, B. (2008). Gastrointestinal symptoms in primary care: prevalence and association with depression and anxiety. J. Psychosom. Res. 64, 605-612. doi: 10.1016/j. jpsychores.2008.02.019

Neunlist, M., Van Landeghem, L., Mahe, M. M., Derkinderen, P., des Varannes, S. B., and Rolli-Derkinderen, M. (2013). The digestive neuronal-glial-epithelial unit: a new actor in gut health and disease. Nat. Rev. Gastroenterol. Hepatol. 10, 90-100. doi: 10.1038/nrgastro.2012.221

Parida, S., Singh, T. U., Thangamalai, R., Narasimha Reddy, Ch. E, Panigrahi, M., Kandasamy, K., et al. (2015). Daidzein pretreatment improves survival in mouse model of sepsis. J. Surg. Res. 197, 363-373. doi: 10.1016/j.jss.2015.03.059

Perrier, C., and Corthesy, B. (2011). Gut permeability and food allergies. Clin. Exp. Allergy 41, 20-28. doi: 10.1111/j.1365-2222.2010.03639.x

Piche, T., Barbara, G., Aubert, P., Bruley des Varannes, S., Dainese, R., Nano, J. L., et al. (2009). Impaired intestinal barrier integrity in the colon of patients with irritable bowel syndrome: involvement of soluble mediators. Gut 58, 196-201. doi: 10.1136/gut.2007.140806

Poritz, L. S., Garver, K. I., Green, C., Fitzpatrick, L., Ruggiero, F., and Koltun, W. A. (2007). Loss of the tight junction protein ZO-1 in dextran sulfate sodium induced colitis. J. Surg. Res. 140, 12-19. doi: 10.1016/j.jss.2006.07.050

Price, E. R., Ruff, L. J., Guerra, A., and Karasov, W. H. (2013). Cold exposure increases intestinal paracellular permeability to nutrients in the mouse. J. Exp. Biol. 216(Pt 21), 4065-4070. doi: 10.1242/jeb.088203

Pull, S. L., Doherty, J. M., Mills, J. C., Gordon, J. I., and Stappenbeck, T. S. (2005). Activated macrophages are an adaptive element of the colonic epithelial progenitor niche necessary for regenerative responses to injury. Proc. Natl. Acad. Sci. U.S.A. 102, 99-104. doi: 10.1073/pnas.0405979102

Randhawa, P. K., Singh, K., Singh, N., and Jaggi, A. S. (2014). A review on chemicalinduced inflammatory bowel disease models in rodents. Korean J. Physiol. Pharmacol. 18, 279-288. doi: 10.4196/kjpp.2014.18.4.279

Ren, C., Dokter-Fokkens, J., Figueroa Lozano, S., Zhang, Q., de Haan, B. J., Zhang, H., et al. (2018). Lactic acid bacteria may impact intestinal barrier function by modulating goblet cells. Mol. Nutr. Food Res. 62:e1700572. doi: 10.1002/mnfr.201700572

Robinson, K., Deng, Z., Hou, Y., and Zhang, G. (2015). Regulation of the intestinal barrier function by host defense peptides. Front. Vet. Sci. 2:57. doi: 10.3389/ fvets.2015.00057

Sandek, A., Bauditz, J., Swidsinski, A., Buhner, S., Weber-Eibel, J., von Haehling, S., et al. (2007). Altered intestinal function in patients with chronic heart failure. J. Am. Coll. Cardiol. 50, 1561-1569. doi: 10.1016/j.jacc.2007.07.016
Sapone, A., de Magistris, L., Pietzak, M., Clemente, M. G., Tripathi, A., Cucca, F., et al. (2006). Zonulin upregulation is associated with increased gut permeability in subjects with type 1 diabetes and their relatives. Diabetes 55, 1443-1449. doi: $10.2337 / \mathrm{db} 05-1593$

Schnabl, B. (2013). Linking intestinal homeostasis and liver disease. Curr. Opin. Gastroenterol. 29, 264-270. doi: 10.1097/MOG.0b013e32835ff948

Severance, E. G., Gressitt, K. L., Stallings, C. R., Origoni, A. E., Khushalani, S., Leweke, F. M., et al. (2013). Discordant patterns of bacterial translocation markers and implications for innate immune imbalances in schizophrenia. Schizophr. Res. 148, 130-137. doi: 10.1016/j.schres.2013.05.018

Sharpstone, D., Neild, P., Crane, R., Taylor, C., Hodgson, C., Sherwood, R., et al. (1999). Small intestinal transit, absorption, and permeability in patients with AIDS with and without diarrhoea. Gut 45, 70-76. doi: 10.1136/gut.45.1.70

Shi, C. Z., Chen, H. Q., Liang, Y., Xia, Y., Yang, Y. Z., Yang, J., et al. (2014). Combined probiotic bacteria promotes intestinal epithelial barrier function in interleukin-10-gene-deficient mice. World J. Gastroenterol. 20, 4636-4647. doi: 10.3748/wjg.v20.i16.4636

Shukla, P. K., Gangwar, R., Manda, B., Meena, A. S., Yadav, N., Szabo, E., et al. (2016). Rapid disruption of intestinal epithelial tight junction and barrier dysfunction by ionizing radiation in mouse colon in vivo: protection by N-acetyl-1-cysteine. Am. J. Physiol. Gastrointest. Liver Physiol. 310, G705-G715. doi: 10.1152/ajpgi.00314.2015

Smythies, L. E., Sellers, M., Clements, R. H., Mosteller-Barnum, M., Meng, G., Benjamin, W. H., et al. (2005). Human intestinal macrophages display profound inflammatory anergy despite avid phagocytic and bacteriocidal activity. J. Clin. Invest. 115, 66-75. doi: 10.1172/JCI200519229

Soderholm, J. D., Peterson, K. H., Olaison, G., Franzen, L. E., Westrom, B., Magnusson, K. E., et al. (1999). Epithelial permeability to proteins in the noninflamed ileum of Crohn's disease? Gastroenterology 117, 65-72.

Sommer, F., and Backhed, F. (2013). The gut microbiota-masters of host development and physiology. Nat. Rev. Microbiol. 11, 227-238. doi: 10.1038/ nrmicro2974

Spiller, R., Aziz, Q., Creed, F., Emmanuel, A., Houghton, L., Hungin, P., et al. (2007). Guidelines on the irritable bowel syndrome: mechanisms and practical management. Gut 56, 1770-1798. doi: 10.1136/gut.2007.119446

Srinivasan, B., Kolli, A. R., Esch, M. B., Abaci, H. E., Shuler, M. L., and Hickman, J. J. (2015). TEER measurement techniques for in vitro barrier model systems. J. Lab. Autom. 20, 107-126. doi: 10.1177/2211068214561025

Steegenga, W. T., de Wit, N. J., Boekschoten, M. V., Ijssennagger, N., Lute, C., Keshtkar, S., et al. (2012). Structural, functional and molecular analysis of the effects of aging in the small intestine and colon of C57BL/6J mice. BMC Med. Genomics 5:38. doi: 10.1186/1755-8794-5-38

Suzuki, T. (2013). Regulation of intestinal epithelial permeability by tight junctions. Cell. Mol. Life Sci. 70, 631-659. doi: 10.1007/s00018-012-1070-x

Tian, J., Hao, L., Chandra, P., Jones, D. P., Willams, I. R., Gewirtz, A. T., et al. (2009). Dietary glutamine and oral antibiotics each improve indexes of gut barrier function in rat short bowel syndrome. Am. J. Physiol. Gastrointest. Liver Physiol. 296, G348-G355. doi: 10.1152/ajpgi.90233. 2008

Tornai, T., Palyu, E., Vitalis, Z., Tornai, I., Tornai, D., Antal-Szalmas, P., et al. (2017). Gut barrier failure biomarkers are associated with poor disease outcome in patients with primary sclerosing cholangitis. World J. Gastroenterol. 23, 5412-5421. doi: 10.3748/wjg.v23.i29.5412

Turner, J. R. (2009). Intestinal mucosal barrier function in health and disease. Nat. Rev. Immunol. 9, 799-809. doi: 10.1038/nri2653

Uhlig, H. H., Schwerd, T., Koletzko, S., Shah, N., Kammermeier, J., Elkadri, A., et al. (2014). The diagnostic approach to monogenic very early onset inflammatory bowel disease. Gastroenterology 147, 990.e3-1007.e3. doi: 10.1053/j.gastro.2014. 07.023

Vancamelbeke, M., and Vermeire, S. (2017). The intestinal barrier: a fundamental role in health and disease. Expert Rev. Gastroenterol. Hepatol. 11, 821-834. doi: 10.1080/17474124.2017.1343143

Vaziri, N. D., Wong, J., Pahl, M., Piceno, Y. M., Yuan, J., DeSantis, T. Z., et al. (2013). Chronic kidney disease alters intestinal microbial flora. Kidney Int. 83, 308-315. doi: 10.1038/ki.2012.345

Vervliet, B., and Raes, F. (2013). Criteria of validity in experimental psychopathology: application to models of anxiety and depression. Psychol. Med. 43, 2241-2244. doi: 10.1017/S0033291712002267 
Viggiano, D., Ianiro, G., Vanella, G., Bibbo, S., Bruno, G., Simeone, G., et al. (2015). Gut barrier in health and disease: focus on childhood. Eur. Rev. Med. Pharmacol. Sci. 19, 1077-1085.

Vivinus-Nebot, M., Frin-Mathy, G., Bzioueche, H., Dainese, R., Bernard, G., Anty, R., et al. (2014). Functional bowel symptoms in quiescent inflammatory bowel diseases: role of epithelial barrier disruption and low-grade inflammation. Gut 63, 744-752. doi: 10.1136/gutjnl-2012-304066

Wagner, C. L., Taylor, S. N., and Johnson, D. (2008). Host factors in amniotic fluid and breast milk that contribute to gut maturation. Clin. Rev. Allergy Immunol. 34, 191-204. doi: 10.1007/s12016-007-8032-3

Wang, L., Llorente, C., Hartmann, P., Yang, A. M., Chen, P., and Schnabl, B. (2015). Methods to determine intestinal permeability and bacterial translocation during liver disease. J. Immunol. Methods 421, 44-53. doi: 10.1016/j.jim.2014.12.015

Worthington, B. S., and Syrotuck, J. (1976). Intestinal permeability to large particles in normal and protein-deficient adult rats. J. Nutr. 106, 20-32. doi: 10.1093/jn/ 106.1.20

Worthington, J. J., Reimann, F., and Gribble, F. M. (2018). Enteroendocrine cellssensory sentinels of the intestinal environment and orchestrators of mucosal immunity. Mucosal Immunol. 11, 3-20. doi: 10.1038/mi.2017.73

Xu, C. L., Guo, Y., Qiao, L., Ma, L., and Cheng, Y. Y. (2018). Recombinant expressed vasoactive intestinal peptide analogue ameliorates TNBS-induced colitis in rats. World J. Gastroenterol. 24, 706-715. doi: 10.3748/wjg.v24.i6.706

Yamamoto, T., Watabe, K., Nakahara, M., Ogiyama, H., Kiyohara, T., Tsutsui, S., et al. (2008). Disturbed gastrointestinal motility and decreased interstitial cells of Cajal in diabetic db/db mice. J. Gastroenterol. Hepatol. 23, 660-667. doi: 10.1111/j.1440-1746.2008.05326.x

Yamamoto-Furusho, J. K., Ascano-Gutierrez, I., Furuzawa-Carballeda, J., and Fonseca-Camarillo, G. (2015). Differential expression of MUC12, MUC16, and MUC20 in patients with active and remission ulcerative colitis. Mediat. Inflamm. 2015:659018. doi: 10.1155/2015/659018

Yoseph, B. P., Klingensmith, N. J., Liang, Z., Breed, E. R., Burd, E. M., Mittal, R., et al. (2016). Mechanisms of intestinal barrier dysfunction in sepsis. Shock 46, 52-59. doi: 10.1097/SHK.0000000000000565

Zhai, Q., Tian, F., Zhao, J., Zhang, H., Narbad, A., and Chen, W. (2016). Oral administration of probiotics inhibits absorption of the heavy metal cadmium by protecting the intestinal barrier. Appl. Environ. Microbiol. 82, 4429-4440. doi: 10.1128/AEM.00695-16

Zhang, J. B., Du, X. G., Zhang, H., Li, M. L., Xiao, G., Wu, J., et al. (2010). Breakdown of the gut barrier in patients with multiple organ dysfunction syndrome is attenuated by continuous blood purification: effects on tight junction structural proteins. Int. J. Artif. Organs 33, 5-14. doi: 10.1177/ 039139881003300102

Zhang, X., and Jiang, X. (2015). Effects of enteral nutrition on the barrier function of the intestinal mucosa and dopamine receptor expression in rats with traumatic brain injury. J. Parenter. Enteral. Nutr. 39, 114-123. doi: 10.1177/ 0148607113501881

Zhao, H., Yu, H., Martin, T. A., Zhang, Y., Chen, G., and Jiang, W. G. (2016). Effect of junctional adhesion molecule-2 expression on cell growth, invasion and migration in human colorectal cancer. Int. J. Oncol. 48, 929-936. doi: 10.3892/ijo.2016.3340

Zheyu, C., Qinghui, Q., and Lunan, Y. (2007). Roles of calcium and IP3 in impaired colon contractility of rats following multiple organ dysfunction syndrome. Braz. J. Med. Biol. Res. 40, 1389-1397. doi: 10.1590/S0100-879X2006005000147

Ziegler, T. R., Smith, R. J., O’Dwyer, S. T., Demling, R. H., and Wilmore, D. W. (1988). Increased intestinal permeability associated with infection in burn patients. Arch. Surg. 123, 1313-1319. doi: 10.1001/archsurg.1988. 01400350027003

Conflict of Interest Statement: The authors declare that the research was conducted in the absence of any commercial or financial relationships that could be construed as a potential conflict of interest.

Copyright (C) 2019 González-González, Díaz-Zepeda, Eyzaguirre-Velásquez, González-Arancibia, Bravo and Julio-Pieper. This is an open-access article distributed under the terms of the Creative Commons Attribution License (CC BY). The use, distribution or reproduction in other forums is permitted, provided the original author(s) and the copyright owner(s) are credited and that the original publication in this journal is cited, in accordance with accepted academic practice. No use, distribution or reproduction is permitted which does not comply with these terms. 